\title{
Planejamento PaRTicipativo E INTEgRado: Desafios A SEREM SUPERADOS EM UMA ESCOLA DE ENSINO MÉDIO INTEGRADO AO TÉCNICO
}

\author{
PARTICIPATORY AND INTEGRATED PLANNING: ESSENTIAL ELEMENT FOR \\ STRENGTHENING OF SCHOOL IDENTITY
}

DOI: http://dx.doi.org/10.23926/RPD.2526-2149.2019.v4.n2.p744-754.id459

\section{Glauce Barros Santos Sousa Araujo \\ Mestra em Ensino (UNIVATES) \\ Professora na FAESF/PI \\ glauce.barros@bol.com.br}

\section{Bruno Bottega \\ Dell'Osbel \\ Graduando do curso de \\ Letras (UNIVATES) \\ bruno.osbel@universo.univat es.br}

\section{Eniz Conceição \\ Oliveira}

Pós-doutorado em Educação pela Universidade de Aveiro (UA)/Portugal

Professora de Química na UNIVATES

eniz@univates.br
Resumo: Este artigo tem como objetivo descrever a importância do planejamento participativo e integrado para o fortalecimento da identidade escolar. A pesquisa realizada tem abordagem qualitativa e exploratória. Para a coleta de dados foi aplicado um questionário semiestruturado no formulário google docs para quatro professores, cada um representando uma área do conhecimento; dois professores das áreas específicas e dois coordenadores. Para a análise dos dados foi optada a análise descritiva. Conclui-se que a forma como o planejamento é desenvolvido na escola investigada vem dificultando a efetivação de um currículo integrado, pois o mesmo é feito de modo individualizado, não participativo e não integrado. Destaca-se, também, que um planejamento, quando realizado de forma que venha aliar a teoria e a prática, contribui para o fortalecimento e identidade da escola, bem como favorece a superação das separações dos conhecimentos, ajudando na concretização da integração.

Palavras-chave: Planejamento participativo; Formação continuada; Identidade escolar.

\begin{abstract}
In this sense, this article has as goal to describe the importance of participatory and integrated planning for strengthening of school identity. The research carried out has the qualitative and exploratory approach. For the data collect was applied a quis semistructured in the google docs form to four teachers, each one representing a knowledge area; two teachers from specific areas and two coordinators. For the data analysis was chosen the descriptive analysis. It was concluded that the way planning is developed at the school has been hampering the implementation of an integrated curriculum, that is done in an individualized way, nonparticipatory and non-integrated. It also stands out that planning allying theory and practice, it contributes for the strengthening and school identity, as well as favors overcoming the separations of knowledge, helping to achieve integration.

Keywords: Participatory planning; Continuing formation; School identity.
\end{abstract}




\section{A IMPORTÂNCIA DO PLANEJAMENTO PARTICIPATIVO E INTEGRAdO}

O planejamento é de suma importância no contexto escolar, pois o mesmo não pode ser desvinculado da realidade onde os sujeitos estão inseridos nem com as relações que o planejamento exerce na escola. Nesse sentido, faz-se necessário que esta interação do ato de planejar de acordo com as reais necessidades dos alunos venha a contribuir na construção de novos conhecimentos e na transformação da realidade onde os sujeitos estão inseridos.

Para Padilha (2001), o planejamento tem como objetivo elaborar respostas a um determinado problema, estabelecidos por intermédio de meios e finalidades, a fim de atingir um determinado objetivo previamente definido. E para que isso aconteça é necessário considerar as circunstâncias e a realidade vivida, assim como as experiências passadas, levando em conta todos os contextos, sejam eles sociopolíticos, sejam culturais do indivíduo que planeja ou com quem se planeja. Já para Molina e Rodriguez (2001), o planejamento estabelece uma aproximação de uma realidade existente com uma realidade pretendida, sendo que ele deve ser uma ferramenta que possa atender às necessidades dos sujeitos, tendo o poder de transformar um determinado acontecimento para atingir um determinado objetivo.

Assim, com base na leitura desses estudiosos, entende-se que o planejamento tem como proposta servir como um mecanismo de transformação da realidade em que se vive, estabelecendo os meios possíveis para atingir o objetivo pretendido. Dessa forma, para que o planejamento seja efetivado de maneira satisfatória para todos, é necessário observar o contexto social, político e cultural dos sujeitos envolvidos, como também os diversos acontecimentos ou fenômenos existentes no espaço escolar.

Na perspectiva de Libâneo (2004), o planejamento nunca deve ser realizado de forma individual, pois é uma atividade coletiva, tanto os planos, quanto as discussões para definição dos objetivos, das atitudes, dos valores, dos conteúdos, assim como na atuação do docente na escola, visando novas atividades para melhoria dos processos ensino e aprendizagem.

Dessa forma, o planejamento participativo assume uma função de promover um ensino de qualidade e satisfatório para todos, pois estimula o trabalho coletivo, bem como trabalha no sentido de descentralizar as ações, eliminando, assim, a fragmentação e ações desarticuladas e sem significados. Diante disso, Matus (1993) comenta que o planejamento deve ser um procedimento constante no cotidiano e que deve servir diariamente como um norte para o trabalho, pois serve como um elo entre a ação e o conhecimento, sabendo que nesse processo de interação pode compreender os outros e a si mesmo quando estes planejam visando objetivos em comum. 
Diante da importância da realização de um planejamento de forma integrada e participativa, em que os sujeitos devem desenvolver atividades coletivas em prol de resultados positivos, aponta-se para a seguinte pergunta de pesquisa: Como é realizado o planejamento no Centro Estadual de Educação Profissional Calisto Lobo?

Assim, este artigo tem como objetivo descrever a importância do planejamento participativo e integrado para o fortalecimento da identidade escolar do Centro Estadual de Educação Profissional Calisto Lobo, no Piauí.

Os dados foram levantados nos meses de agosto e setembro de 2018 por meio de um questionário semiestruturado no formulário google docs, constituído de perguntas abertas e itens curtos, utilizando a análise descritiva para a análise dos dados da pesquisa.

Como forma de estruturar este estudo, na primeira parte discorreremos sobre a importância do planejamento participativo e integrado, e, em seguida, apresentaremos a metodologia utilizada e os resultados e discussão, bem como as considerações finais acerca da temática abordada.

\section{Metodologia}

Este estudo foi realizado no Centro Estadual de Educação Profissional Calisto Lobo Floriano/Piauí, onde oito sujeitos da pesquisa responderam um questionário semiestruturado no formulário google docs, em que o mesmo foi enviado a todos os respondentes por e-mail, dentre eles: quatro professores das áreas de conhecimentos gerais, dois professores de áreas específicas e dois coordenadores, os quais foram nomeados P1 a P6 e C1 e C2, respectivamente. Relata-se também que todos os participantes da pesquisa assinaram um Termo de Consentimento Livre e Esclarecido - TCLE.

Estes participantes foram escolhidos mediante observação assistemática e participante dos pesquisadores, como: comprometimento e empenho dos mesmos na escola, assim como sujeitos disponíveis e acessíveis, de modo a satisfazer os objetivos propostos pela pesquisa. Salienta-se que todos os professores possuem graduação nas áreas de atuação e trabalham há mais de 8 anos na referida escola. Os coordenadores participantes da pesquisa possuem graduação e exercem a função há mais de três anos no Centro Estadual de Educação Profissional Calisto Lobo.

De acordo com Minayo (2009), a análise de dados é uma técnica de pesquisa que permite validar os dados a partir de procedimentos especializados. Dessa forma, para a análise 
dos dados, foi utilizada a análise descritiva, que consiste na observação de conteúdo ocorrido no campo (BOGDAN e BIKLEN, 1994).

A pesquisa tem uma abordagem qualitativa, exploratória e bibliográfica, onde a investigação acontece de forma interpretativa e os fatos são descritos não de maneira matemática e numérica. Segundo Oliveira (2002), a pesquisa qualitativa permite um aprofundamento dos fatos, levando em conta as intepretações e atitudes dos sujeitos.

A pesquisa exploratória, de acordo com Mattar (2001), tem como intuito aprofundar o tema ou possibilitar que o pesquisador tenha um maior conhecimento sobre a temática ou o assunto pesquisado.

Para a análise de dados foi utilizada a análise descritiva, que, segundo Prodanov (2013), possibilita que as diversas situações possam ser analisadas, interpretadas e registradas pelo pesquisador. Nesse sentido, a investigação foi realizada em uma escola de ensino médio integrado ao técnico na cidade de Floriano - Piauí, onde possibilitou que os dados fossem coletados e registrados a fim de obter os resultados propostos pela pesquisa.

\section{Resultados e Discussão}

Para que os objetivos traçados pela escola possam ser alcançados, é necessário que os planejamentos sejam feitos de forma coletiva e integrada, com a participação de todos os envolvidos, imbuídos em um único propósito: o de efetivar um ensino de qualidade que melhore a aprendizagem dos alunos. Os professores do Centro Estadual de Educação Profissional Calisto Lobo enfatizaram que o planejamento realizado na escola é feito de forma individualizada, como se observam nas respostas seguintes:

O planejamento é feito individualmente, cada professor realiza seu planejamento de forma individualizada, mesmo quando o professor ministra a mesma disciplina dos demais professores, não fazemos o planejamento junto para que o conteúdo seja igualmente ministrado por todos (P4).

Desse modo, percebe-se que o planejamento realizado pelos professores da escola é de forma individualizada, dificultando, assim, um trabalho integrado e participativo, contribuindo para um trabalho sistematizado e não articulado com os demais envolvidos no processo educacional.

O planejamento na escola deve ser entendido por todos como sendo um processo contínuo de reflexões e ações realizado por toda comunidade escolar frente aos problemas da realidade em que todos estão inseridos, a fim de que possam ser traçados objetivos comuns, no intuito da obtenção dos resultados satisfatórios para todos. Desta forma, quando este 
planejamento é feito de forma individualizada, não é possível traçar objetivos em sua integralidade.

Gandin (2004) relata que o planejamento deve ser visto como uma tarefa natural do indivíduo, sendo este um processo de organização de ideias, em que se representa algo a desejar em prol de uma transformação da realidade, seja em parte ou em sua totalidade.

Sabe-se que a escola contribui de forma positiva na formação humana, pois é por meio das experiências que os sujeitos possuem fora da escola e juntamente com as experiências adquiridas nos espaços escolares que eles se formam como indivíduos autônomos, críticos e conscientes de suas ações, atuando de forma participativa no contexto onde estão inseridos. Nesse sentido, Araújo (2002) ressalta que a escola deve propiciar práticas pedagógicas que promovam a participação de todos no que se diz respeito às deliberações do trabalho, aos conteúdos, assim como o convívio coletivo.

Oliveira e Brito (2016) relatam que o planejamento participativo tem como intuito democratizar as ações, estabelecendo prioridades entre os sujeitos envolvidos, efetivando assim o exercício da cidadania, na medida que os objetivos e ações são traçadas para atingir os resultados de mudanças e transformações no contexto onde estão entrelaçados. De acordo com Gandin (2004), o planejamento participativo contribui para socialização dos mais diversos saberes, ações e ideias, onde todos têm a oportunidade de crescer, inovar e transformar a realidade em esforços coletivos e democráticos.

O planejamento deve ser visto como uma ação coletiva em que os diversos segmentos devem estar envolvidos no processo, discutindo e decidindo ações coletivas para que os objetivos traçados sejam atingidos, em que possam solucionar em conjunto os diversos problemas existentes na escola, efetivando assim um trabalho coletivo e democrático. Deduzse que quando a escola trabalha de forma coletiva e participativa, envolvendo toda a comunidade escolar em todas as atividades, os alunos têm possibilidade de exercer a sua autonomia, bem como contribuir para a efetivação de suas vivências visando adquirir conhecimentos de forma a dar sentido à sua vida, aliando teoria e prática, contribuindo para o desenvolvimento dos estudantes de maneira plena e significativa para todos.

É de significativa conta que o planejamento realizado na instituição pesquisada possa ser efetivado de forma participativa e integrada por toda a comunidade escolar, para que, assim, os alunos possam adquirir conhecimentos de forma satisfatória e de qualidade, bem como promover um convívio coletivo entre todos. 
Para Vasconcellos (2000), o docente precisa desejar realizar o planejamento, pois a motivação vem como forma de fazer do planejamento um ato de mudança da realidade, é preciso saber que esta mudança não acontecerá de forma espontânea ou simplesmente com a vontade de realizar. Portanto, é de suma importância que o docente possa se sentir parte do processo de planejar e que contribua na melhoria da aprendizagem dos estudantes.

Nessa linha de pensamento, é necessário reforçar que o planejamento seja realizado de forma coletiva, participativa e motivadora, e não apenas como um ato motivador e idealizado unicamente por um professor, mas que seja um desejo de todos, para que possa contribuir no desenvolvimento do aluno, promovendo a construção do conhecimento de forma satisfatória para todos, atendendo às suas reais necessidades.

É de suma importância que o planejamento seja realizado de forma participativa, para que assim os sujeitos possam refletir sobre as ações em busca de mudanças e transformações positivas para atingir os resultados pretendidos, agindo sempre de forma coletiva em prol da firmação da identidade escolar.

Nesse sentido, percebemos que um planejamento participativo e integrado contribui de forma positiva na melhoria dos resultados da escola e do ambiente escolar. Desse modo a figura 1 ilustra os elementos que estão entrelaçados quando o planejamento participativo e integrado é efetivado em sua prática.

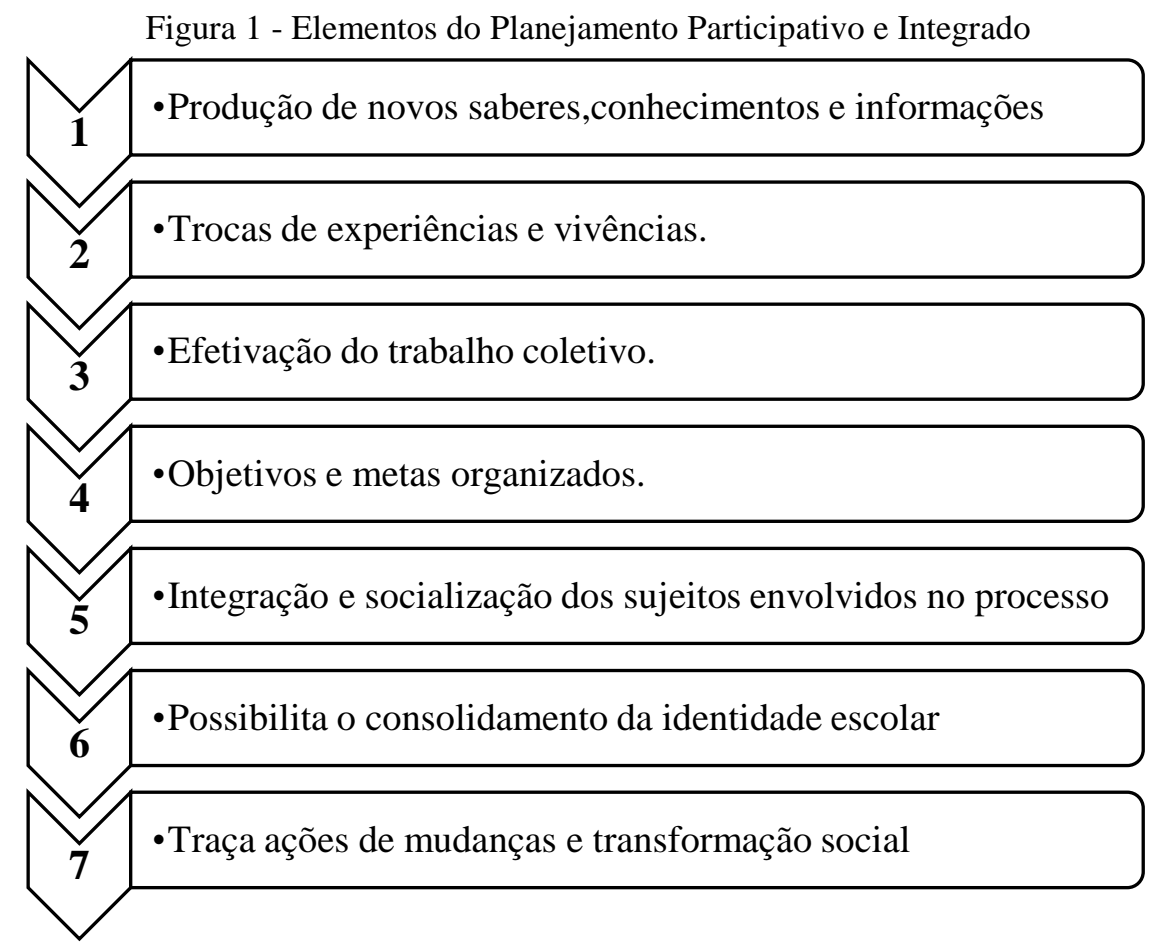

Fonte: Dos autores (2019). 
No Centro Estadual de Educação Profissional Calisto Lobo encontram-se professores preocupados quanto à forma como são realizados os planejamentos na escola, o que fica evidenciado na fala do respondente ao questionário: "Está faltando um planejamento integrado entre os professores, pois cada docente elabora seu planejamento" (P1).

Vasconcellos (2000) enfatiza que o professor, quando se compromete em fazer um planejamento, possibilita que o mesmo possa refletir constantemente sobre a realidade no qual está inserido, bem como pensar nos objetivos a alcançar e em sua prática enquanto docente.

O mesmo autor relata que o maior desafio do planejamento está no poder da transformação, inovação e ousadia, no sentido de ultrapassar as barreiras existentes, sendo que realizar um planejamento que venha atender a realidade depende de compromissos e esforços de sujeitos tanto na elaboração quanto na execução das ações a serem realizadas, a fim da obtenção dos objetivos almejados.

Na perspectiva de Casagrande e Begnini (2014), uma instituição forma-se quando existe a união de empenhos individuais com a finalidade de atingir objetivos coletivos, pois é por meio de uma instituição que é possível alcançar resultados que antes, individualmente, eram impossíveis de serem atingidos.

Souza et al. (2005) relatam que o planejamento participativo deve acontecer de forma contínua e organizada, tendo que ser elaborada com todos os envolvidos no processo, onde a integração e o poder de decisão deve ser de forma coletiva, para que assim possam direcionar as ações de forma efetiva e transformadora.

Por esse ponto de vista, é importante a realização de um planejamento que aconteça com a participação de toda a comunidade escolar, estimulando a integração dos conteúdos, com o intuito de alcançar melhorias de aprendizagens, a fim de que possam atingir os objetivos propostos pela instituição de ensino.

No Centro Estadual de Educação Profissional Calisto Lobo ainda se encontram professores estimulados a realizar um planejamento participativo e integrado, mas em suas mais diversas situações no dia a dia da escola a concretização desse planejamento participativo não é executada, como se observa no relato do professor: "Até tentamos planejar em grupos, mas na maioria das vezes ocorre de forma individual, seguindo o plano de curso" (P3).

Vasconcellos (2000) enfatiza que o planejamento segue uma perspectiva de mudança da realidade. Diante disso, é imprescindível que os professores sintam a necessidade de mudança e transformação da realidade e percebam que o planejamento não é um elemento 
apenas para comprovação de ações e atividades, mas um instrumento indispensável para o aperfeiçoamento das práticas e ações realizadas na escola.

De acordo com Ganzeli (2001), a participação dos sujeitos no planejamento deve ser entendida como um processo de aprendizagem que necessita de espaços, tempos e esforços para a sua efetivação, para que as ideias sejam discutidas e analisadas e que todos possam estar envolvidos com a formação integral do aluno, como também para uma concretização de espaços democráticos.

Nesse sentido, para a realização de um planejamento participativo, são necessários esforços tanto por parte dos envolvidos, como também pela instituição escolar, pois demanda tempo, espaço e empenho para o seu cumprimento. Observa-se que quando esse planejamento é realizado de forma participativa e integrada contribui de modo positivo no desenvolvimento do aluno e efetivação de uma escola genuinamente democrática.

Em uma escola de ensino médio integrado é de suma importância que o planejamento seja elaborado, aliando os conteúdos teóricos juntamente com os conhecimentos práticos, a fim de superar as dualidades existentes entre os conhecimentos gerais e específicos. Nesse sentido, apresenta-se o relato do coordenador: "O planejamento das aulas é feito de acordo com a realidade da turma, sempre aliando teoria com a prática" (C2).

Simões (2007) relata que o ensino médio integrado ao técnico proporciona que os sujeitos adquiram conhecimentos que contribuam em sua vida social, bem como em sua vida econômica, e que os mais diversos saberes aprendidos na escola devem contribuir para o desenvolvimento e transformação da realidade dos mesmos.

Desse modo, o planejamento, quando realizado de forma coletiva com os demais professores, sejam eles de áreas gerais ou específicas, possibilita que as ações sejam pensadas e articuladas entre todos, no intuito de direcionar as atividades mais próximas da realidade dos indivíduos de forma integrada e não separada, contribuindo no desenvolvimento dos alunos de forma plena e em sua totalidade.

Souza et al. (2005) comentam que a relação entre a teoria e a prática se insere nas mais diversas condições, ora produzindo aproximações, ora produzindo afastamentos entre elas. Desse modo, deve haver unidade entre a teoria e a prática no ato de planejar, servindo assim como práticas positivas no que concerne as ações a serem efetivadas.

Segundo Garcia (2009), para que a escola fortaleça a sua identidade, é relevante que os conhecimentos sejam elaborados em sua prática, como forma de superar as dualidades presentes, em que ora esses conhecimentos perpassam a preparação do vestibular, ora 
perpassam a preparação para as atividades produtivas. A respeito dessa superação, o autor comenta que suplantar essas dualidades existentes não é tornar uma escola única para todos os sujeitos, mas fazer com que essas diferenças colaborem para um ser integrativo.

De acordo com Orso (2015), para que o planejamento seja efetivamente transformado, este não deve ser realizado de forma autoritária, nem tão pouco realizada de forma rígida e inflexível.

Nesse sentido, um planejamento quando realizado de forma que venha aliar a teoria e a prática contribui para o fortalecimento e identidade da escola, bem como favorece a superação das separações dos conhecimentos, ajudando na concretização da integração. Quando o planejamento é realizado de forma em que todos os sujeitos possam integrar-se nas ações coletivas, e quando este possibilita mudanças quando necessárias, não seguindo um único padrão, mas oportunizando novas formas de organizações e aprendizagens contribui para um melhor desenvolvimento potencializando as ações de mudanças esperadas com a realização da mesma.

\section{CONSIDERAÇÕES FINAIS}

O planejamento realizado no Centro Estadual de Educação Profissional Calisto Lobo não acontece de forma participativa e integrada, o que pode contribuir como um elemento que dificulta o trabalho de um currículo integrado. O planejamento participativo assume uma função de promover um ensino de qualidade e satisfatório para todos, pois estimula o trabalho coletivo, bem como trabalha no sentido de descentralizar as ações, eliminando, assim, a fragmentação e ações desarticuladas e sem significados.

Nesse sentido, é importante a realização de um planejamento que aconteça com a participação de toda a comunidade escolar, estimulando a participação e integração dos conteúdos com o intuito de alcançar melhorias de aprendizagens, como também proporcionar o trabalho coletivo com a finalidade de atingir os objetivos de forma que venha atender a todos, e não apenas alguns grupos individualizados ou que aconteça um planejamento de forma fragmentada e desvinculada da realidade dos estudantes.

Destaca-se também, que um planejamento quando realizado de forma que venha aliar a teoria e a prática contribui para o fortalecimento e identidade da escola, bem como favorece a superação das separações dos conhecimentos, ajudando na concretização da integração. 


\section{REFERÊNCIAS}

ARAÚJO, Ulisses Ferreira. A construção de escolas democráticas: histórias sobre complexidade, mudanças e resistências. São Paulo: Moderna, 2002.

BOGDAN, Robert C.; BIKLEN, Sari Knopp. Investigação qualitativa em educação: uma introdução à teoria e aos métodos. Porto: Porto Editora, 336 p., 1994.

CASAGRANDE, Andrea; BEGNINI, Sérgio. Educação integral em tempo integral: O planejamento como ferramenta na gestão. Revista do Centro do Ciências Naturais e Exatas - UFSM, Santa Maria, RS, v. 18, n. 4, p.1430-1442, dez. 2014. Disponível em:

https://periodicos.ufsm.br/reget/article/view/15089/pdf. Acesso em 27 de out. de 2018.

GANDIN, Danilo. A prática do planejamento participativo: na educação e em outras instituições, grupos e movimentos cultural, social, político, religioso e governamental. Petrópolis: Vozes, 2004.

GANZELI, Pedro. O Processo de Planejamento Participativo da Unidade Escolar. Revista on line de política e gestão educacional, Araraquara, São Paulo, n. 1, p. 1-16, 2001. DOI prefix: 10.22633/rpge. Disponível em: https://periodicos.fclar.unesp.br/rpge/article/view/9129. Acesso em: 14 de nov. de 2018.

GARCIA, Sandra Regina de Oliveira. A educação Profissional Integrada ao Ensino Médio no Paraná: avanços e desafios. 2009. 148 p. Tese (Doutorado em Educação) - Universidade Federal do Paraná, Curitiba, 27 fev. 2009. Disponível em: http://www.ppge.ufpr.br/teses/ D09_oliveiragarcia.pdf. Acesso em: 14 de nov. de 2018.

LIBÂNEO, José Carlos. Organização e Gestão da Escola: teoria e prática. 5. ed. Goiânia: Alternativa, 2004.

MATTAR, Fauze Najib. Pesquisa de Marketing: Edição Compacta. São Paulo: Editora Atlas, 2001.

MATUS, Carlos. Política, planejamento \& governo. 2. ed. Brasília: IPEA, Série IPEA, 143, v. 2, p. 4-481, 1993. Disponível em: https://pt.scribd.com/document/285785802/Matus-

Politica-Planejamento-e-Governo-Tomo-I. Acesso em 27 de out. de 2018.

MINAYO, Maria Cecília de Souza. O desafio da pesquisa social. In: Pesquisa Social: teoria, método e criatividade. 28. ed. Petropólis, Rio de Janeiro: Vozes, 2009. Disponível em: http://www.mobilizadores.org.br/wp-content/uploads/2015/03/MINAYO-M.-

Cec\%C3\%ADlia-org.-Pesquisa-social-teoria-m\%C3\%A9todo-e-criatividade.pdf. Acesso 23 de mar. de 2019.

MOLINA, Sergio; RODRÍGUEZ, Sergio. Planejamento Integral do Turismo. Bauru, SP: EDUSC, 2001.

OLIVEIRA, Eva Maria; BRITO, Islândia Maria Ferreira. Planejamento Participativo: Uma ação conjunta com os docentes. Revista Id on line. Rev. Psc. v. 10, n 31. Supl. 3, out/nov, 2016. Disponível em: https://idonline.emnuvens.com.br/id/article/view/527/758. Acesso em 23 de mar. de 2019. 
OLIVEIRA, Silvio Luiz de. Tratado de Metodologia Científica. Projetos de pesquisas, TGI, TCC, monografias, dissertações e teses. Editora, Pioneira, Florianopólis, 2002.

ORSO, José Paulino. Planejamento Escolar em Tempos de Precarização da Educação.

Revista Histedbr on-line, Campinas, $n^{\circ} 65$, out. 2015. Disponível em:

https://periodicos.sbu.unicamp.br/ojs/index.php/histedbr/article/view/8642710. Acesso em 23 de mar. de 2018.

PADILHA, Paulo R. Planejamento Dialógico: Como construir o Projeto Político Pedagógico da escola. São Paulo: Cortez, 2001.

PRODANOV, Cleber Cristiano. Métodos e técnicas da pesquisa e do trabalho acadêmico.

2. ed. Novo Hamburgo: Feevale, 2013.

SOUZA, Ângelo Ricardo de; GOUVEIA, Andréa Barbosa; SILVA, Monica Ribeiro da; SCHWENDLER. Gestão da Escola Pública. Caderno 2: Planejamento e Trabalho Coletivo. Curitiba: UFPR, 2005. Disponível em:

http://www.gestaoescolar.diaadia.pr.gov.br/arquivos/File/sem_pedagogica/fev_2010/planejam ento_trabalho_coletivo.pdf. Acesso em 23 de mar. de 2019.

SILVA, Regina da. Planejamento Educacional Participativo. Tendo como Princípio a Gestão Democrática. Monografia de Especialização Latu Sensu em Gestão Educacional à Distância. Universidade Federal de Santa Maria. Polo Tio Hugo, RS, 2014. Disponível em: https://repositorio.ufsm.br/bitstream/handle/1/12896/TCCE_GE_EaD_2014_SILVA_REGIN A.pdf? sequence $=1 \&$ is Allowed $=y$. Acesso em 28 de dez. de 2018.

SIMÕES, Carlos Artexes. Juventude e Educação Técnica: a experiência na formação de jovens trabalhadores da Escola Estadual Prof. Horácio Macedo/CEFET-RJ. 138 f. Dissertação (Mestrado em Educação) - Universidade Federal Fluminense, Niterói, 2007.

VASCONCELLOS, Celso dos Santos. Planejamento: Projeto de ensino-aprendizagem e Projeto Político-Pedagógico - elementos metodológicos para elaboração e realização. 7. ed. São Paulo: Libertad, 2000.

Recebido em: 17 de maio de 2019.

Aprovado em: 16 de dezembro de 2019. 